\title{
Effect of variability in gas analysis on the reproducibility of the pulmonary diffusing capacity by the single breath method
}

\author{
J. E. COTES
}

From the Medical Research Council, Pneumoconiosis Research Unit, Llandough Hospital, Penarth, Glam.

The single breath pulmonary diffusing capacity (Krogh, 1915; Forster, Fowler, Bates, and Van Lingen, 1954) is often used as an index of exposure to respirable hazards or to provide evidence in assessment for compensation. If it is to be of value, random technical errors and biases should be small compared with variability between subjects. Faults may, for example, arise in analysis of gases or in the collection of samples for analysis. To check on analysis difficulties gas samples, such as might be found in clinical practice, were sent to 21 different laboratories and the results were compared.

This paper shows that errors and biases in gas analysers may be important sources of error at the present time. Standardization of the precise techniques for the inhalation and exhalation of a single breath of test gas will be considered in a subsequent paper (Cotes et al., in preparation).

\section{METHODS}

Through the courtesy of the British Oxygen Company, three master cylinders ( $\mathrm{Bi}, \mathrm{Bii}$, and Biii) containing carbon monoxide and helium in concentrations such as are commonly found in the inspired and expired gas samples in the measurement of the pulmonary diffusing capacity were prepared. The composition of mixture $\mathrm{Bi}$ resembled that commonly inspired during the estimation of diffusing capacity by the single breath method. The composition of mixtures Biii and Bii resembled alveolar samples obtained from normal and abnormal subjects after a 10-second breath-holding period at an alveolar volume of 6 litres. The mixed gases in each cylinder were then decanted into smaller cylinders; these were first evacuated and flushed four times with the same gas mixture to eliminate contamination with air. The effectiveness of this procedure was subsequently confirmed.

The sample cylinders were allocated numbers from 1 to 45 at random and distributed in pairs to the participating laboratories on three occasions at approximately monthly intervals. They were subsequently collected and their contents analysed for helium and carbon monoxide using a katharometer and infra-red analyser of known accuracy (Meade, in preparation). Twelve laboratories reported analysis results on the three mixtures for both carbon monoxide and helium on two separate occasions. The remainder either analysed the cylinders once or only reported results for carbon monoxide. The results were examined without knowledge from which laboratory the values came: their reproducibility was considered in terms of both absolute concentrations and ratios of concentrations for helium and carbon monoxide. The ratios were subsequently expressed as 'diffusing capacities'.

\section{RESULTS}

ABSOLUTE CONCENTRATIONS OF HELIUM AND CARBON MONOXIDE Twelve laboratories reported results for both carbon monoxide and helium on two samples from each master cylinder. Of the 12 , one found no carbon monoxide in two of the samples; another reported helium concentrations in one pair of cylinders which were exactly $50 \%$ of those reported by them on a subsequent occasion; these latter results were adjusted by a factor of two and then included with those from the remaining 10 laboratories in an analysis of reproducibility.

Reproducibility within laboratories The mean values and the standard errors of individual measurements expressed as a percentage of the mean are listed in Table $\mathrm{I}$. The range of the resulting percentage errors for helium in the three cylinders is $1 \cdot 17$ to $1.40 \%$; that for carbon monoxide is 1.51 to $2 \cdot 45 \%$. These results can be considered satisfactory.

Reproducibility between laboratories The spread of results between laboratories is expressed as a standard deviation in Table I. The standard deviation for helium represents 3.25 to $4.0 \%$ of the mean value; the corresponding percentage for carbon monoxide is 8.6 to $12.6 \%$, which is materially greater.

RATIOS OF CONCENTRATIONS OF HELIUM AND CARBON MONOXIDE The following results were obtained. 
TABLE I

ANALYSIS OF ABSOLUTE CONCENTRATIONS OF HELIUM AND CARBON MONOXIDE BY 11 LABORATORIES

\begin{tabular}{|c|c|c|c|c|c|c|}
\hline \multirow[t]{2}{*}{$\begin{array}{l}\text { Gas } \\
\text { Mixture }\end{array}$} & \multicolumn{2}{|c|}{$\begin{array}{l}\text { Mean Values } \\
(\%)\end{array}$} & \multicolumn{2}{|c|}{$\begin{array}{l}\text { Standard Deviation } \\
(\% \text { of mean })\end{array}$} & \multicolumn{2}{|c|}{$\begin{array}{l}\text { Standard Error of } \\
\text { Differences between } \\
\text { Duplicates } \\
(\% \text { of mean })\end{array}$} \\
\hline & Helium & $\begin{array}{l}\text { Carbon } \\
\text { Monoxide }\end{array}$ & $e^{\text {Helium }}$ & $\begin{array}{l}\text { Carbon } \\
\text { Monoxide }\end{array}$ & Helium & $\begin{array}{l}\text { Carbon } \\
\text { Monoxide }\end{array}$ \\
\hline $\begin{array}{l}\text { Bi } \\
\text { Bii } \\
\text { Biii }\end{array}$ & $\begin{array}{r}13 \cdot 20 \\
6 \cdot 13 \\
11 \cdot 81\end{array}$ & $\begin{array}{l}0 \cdot 210 \\
0 \cdot 071 \\
0 \cdot 116\end{array}$ & $\begin{array}{l}4 \cdot 0 \\
3 \cdot 25 \\
3 \cdot 42\end{array}$ & $\begin{array}{r}12 \cdot 6 \\
8 \cdot 6 \\
9 \cdot 9\end{array}$ & $\begin{array}{l}1 \cdot 40 \\
1 \cdot 17 \\
1 \cdot 17\end{array}$ & $\begin{array}{l}2.45 \\
1.78 \\
1.51\end{array}$ \\
\hline
\end{tabular}

Bias within laboratories The three gas mixtures were sent to laboratories in pairs on three occasions so that each gas mixture was analysed twice; however, each pair of gas mixtures was only analysed once so no estimate of reproducibility within laboratories of the resulting ratio could be obtained. Evidence for a bias in the analysis of ratios of concentration was sought by comparison of the ratios reported for the two pairs of cylinders $(\mathrm{Bi}$ and $\mathrm{Biii}$ and $\mathrm{Bi}$ and $\mathrm{Bii}$ ) which were subsequently used for the calculation of 'diffusing capacity'. No bias was detected in the reported ratios of concentration for helium in the two pairs of cylinders (Fig. 1). A significant bias was found to exist amongst the reported ratios of concentration for carbon monoxide; laboratories which reported a high ratio on the first occasion did so on the second occasion and vice versa (Fig. 2).

Reproducibility between laboratories The range of the ratios of concentration reported by the 11 laboratories which submitted results on the analysis of three pairs of gas mixtures was analysed on a proportional basis. The proportional standard error for helium was found to represent $2 \cdot 22$ to $2.51 \%$ of the mean values for the three pairs of gas mixtures; the corresponding value for carbon monoxide $(9.08$ to $12.5 \%)$ was significantly higher (Table II). Thus there is good agreement between laboratories in the analysis of helium ratios but a wide scatter due to systematic bias between laboratories in the analysis of carbon monoxide ratios. These differences are reflected in the 'diffusing capacities' which may be derived from the data.

Effect on the diffusing capacity Assuming a breath-holding time of 10 seconds and an alveolar volume of 6 litres, the gas compositions of cylinders $\mathrm{Bi}$ and Bii represent a 'diffusing capacity' of 14.5 $\mathrm{ml} . / \mathrm{min} . / \mathrm{mm}$. $\mathrm{Hg}$, and of cylinders $\mathrm{Bi}$ and Biii a 'diffusing capacity' of $22.3 \mathrm{ml} . / \mathrm{min} . / \mathrm{mm}$. $\mathrm{Hg}$. The ranges reported by the participating laboratories are respectively 6.7 to $24.8 \mathrm{ml}$. $/ \mathrm{min}$. $/ \mathrm{mm}$. $\mathrm{Hg}$ (i.e., $46 \%$ to $171 \%$ of the expected value) and 18.0 to $29.8 \mathrm{ml} . / \mathrm{min} . / \mathrm{mm}$. $\mathrm{Hg}$ (i.e., $81 \%$ to $134 \%$ of the expected value).

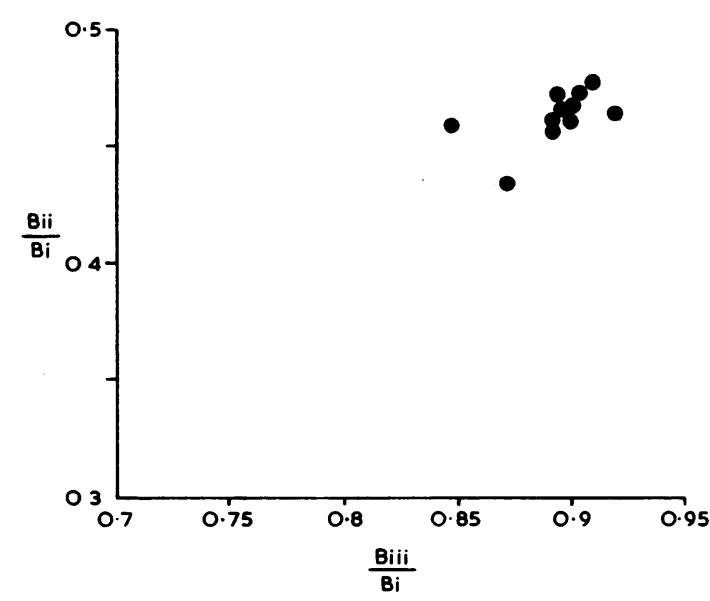

FIG. 1. Comparison of ratios of helium concentrations of two pairs of cylinders analysed by 11 laboratories.

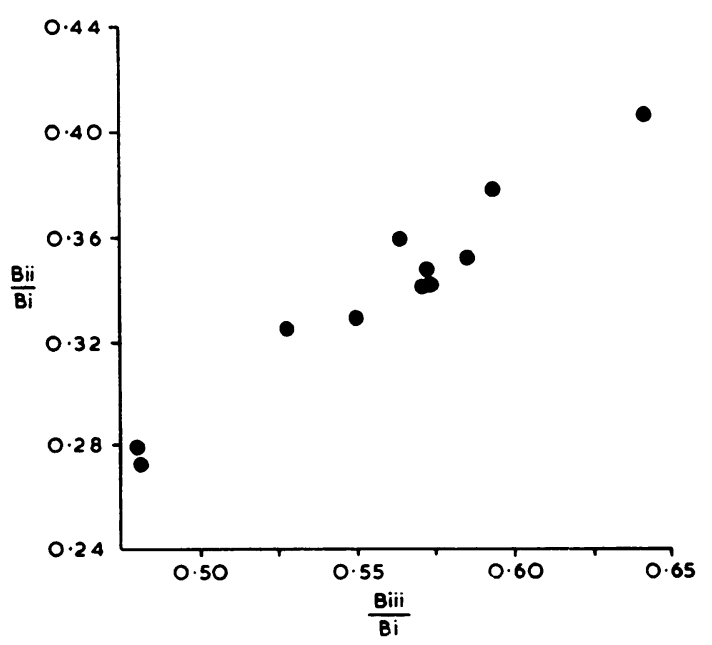

FIG. 2. Comparison of ratios of carbon monoxide concentrations of two pairs of cylinders analysed by 11 laboratories.

\section{TABLE II}

PROPORTIONAL STANDARD ERRORS FOR CONCENTRATION RATIOS OF HELIUM AND CARBON MONOXIDE IN PAIRS OF GAS CYLINDERS ANALYSED BY DIFFERENT LABORATORIES

\begin{tabular}{|c|c|c|c|c|}
\hline & \multicolumn{2}{|c|}{ Helium Ratio } & \multicolumn{2}{|c|}{ Carbon Monoxide Ratio } \\
\hline & Mean & S.E. (\%) & Mean & S.E. $(\%)$ \\
\hline$\frac{\overline{B i i i}}{\overline{\mathbf{B i}}}$ & 0.893 & $2 \cdot 22$ & 0.556 & $9 \cdot 08$ \\
\hline$\frac{\text { Bii }}{\overline{\text { Biii }}}$ & 0.518 & $2 \cdot 23$ & 0.603 & $10 \cdot 90$ \\
\hline $\begin{array}{l}\mathbf{B i i} \\
\overline{\mathbf{B i}}\end{array}$ & 0.464 & $2 \cdot 51$ & $0 \cdot 338$ & $12 \cdot 5$ \\
\hline
\end{tabular}




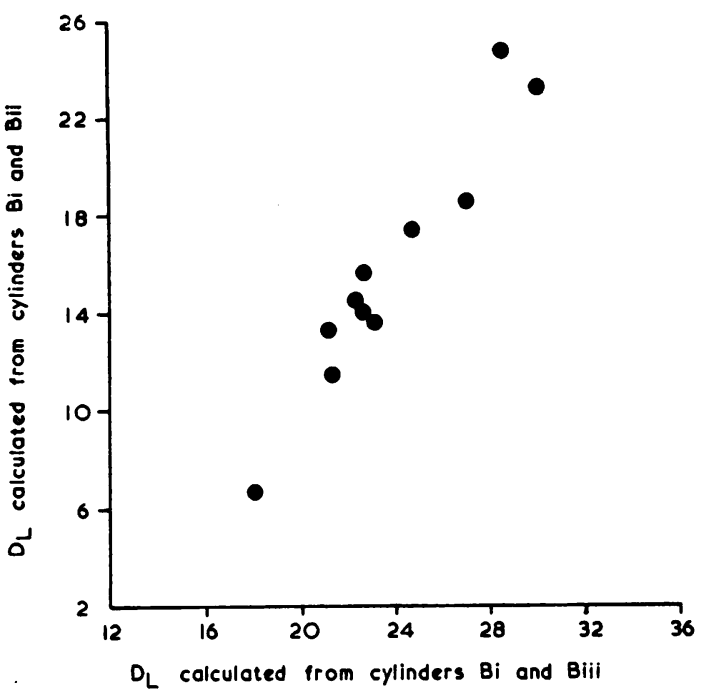

FIG. 3. Comparison of 'diffusing capacities' calculated from the composition of two pairs of cylinders analysed by 11 laboratories.

\section{TABLE III}

MEAN VALUES AND STANDARD DEVIATIONS FOR 'DIFFUSING CAPACITY' CALCULATED FROM COMPOSITION OF PAIRS OF CYLINDERS ANALYSED BY DIFFERENT LABORATORIES

\begin{tabular}{llllll} 
& \multicolumn{2}{c}{ Cylinders $B i$ and $i i$} & & \multicolumn{2}{c}{ Cylinders $B i$ and iii } \\
\cline { 2 - 3 } & Mean & S.D. & & Mean & $S . D$. \\
\hline CO and He & 15.8 & 5.15 & & 23.7 & 3.46 \\
CO (He constant) & 15.8 & 5.86 & & 23.7 & 4.34 \\
He (CO constant) & 15.5 & 1.28 & & 23.5 & 1.11
\end{tabular}

As might be anticipated from the analysis of ratios of concentration for carbon monoxide, there is a high correlation between the two sets of results from each laboratory (Fig. 3). The scatter between laboratories is described by the standard deviations of the mean 'diffusing capacities' derived from the ratio of concentration for the two pairs of cylinders. These are respectively 5.15 and $3.46 \mathrm{ml} . / \mathrm{min} . / \mathrm{mm}$. $\mathrm{Hg}$. They are not reduced when the mean helium concentration ratio for each pair of cylinders is substituted for the individual values in the calculation. However, when the mean carbon monoxide concentration ratio is fed into the calculation the scatter all but disappears (Table III). This is further evidence that variability between laboratories is due to scatter in the results for carbon monoxide.

\section{DISCUSSION}

Systematic differences are to be anticipated when measurements of pulmonary diffusing capacity are made in a number of laboratoi ies, on account of inability to analyse ratios of carbon monoxide concentration correctly. The error may not be as large in practice as the results of this trial would suggest since the laboratory reporting very low 'diffusing capacities' is in the habit of using carbon monoxide concentrations in the range 0 to $0.05 \%$ to minimize errors in its analysis. The spread of results between the remaining laboratories is nevertheless considerable.

Most laboratories use a Luft type analyser for the analysis of carbon monoxide. In this instrument infra-red radiation traverses two parallel light paths which lead to the two sides of the detector. This is essentially a condenser immersed in the gas to which the detector is sensitive. One plate of the condenser is perforated and mounted rigidly, the other is attached to a mobile diaphragm. Absorption of infra-red radiation by the unknown gas which occupies one of the two light paths reduces the amount received by that side of the detector; the resulting pressure differences across the condenser cause movement of the diaphragm and hence a change in electrical capacity. In time, gas leaks from the detector and water vapour seeps in, especially when the humidity is high. These changes cause loss of sensitivity particularly for higher concentrations; their occurrence to varying degrees in the analyser detectors of those participating in the trial may explain some of the low values reported. High values may be due to faulty calibration.

Departure from linearity of the instrument calibration curve will be detected if regular calibrations are carried out at three or more test concentrations. This was not done regularly by at least 11 of the 21 participating laboratories. To reduce errors due to alinearity there is need for:

(1) Greater awareness of the possibility that it may occur. This is the responsibility of the manufacturer supplying the instrument.

(2) Simplification of the calibration procedure. This would be assisted if there was a better supply of gas mixtures of known concentration. The steel cylinders used to store such standard mixtures should be tin-lined as carbon monoxide reacts with iron. Even in tin-lined cylinders the carbon monoxide concentration may decrease by 2 to $3 \%$ per annum (Bartley, 1962, personal communication) so the standards should be reviewed every 6 to 12 months. The gas should be stored dry. Clean hydrogen quality steel cylinders (Shepherd, 1947) may also be used where these are available.

As an alternative to the use of standard mixtures, calibration can be carried out by serial dilution of carbon monoxide to which helium is added as an indicator. Dilution can be performed in the closedcircuit spirometer used for the determination of 
lung volumes, when the fall in concentration of helium in the circuit indicates the change in concentration of carbon monoxide. This procedure effectively calibrates the infra-red gas analyser against the helium katharometer which, in the present series, was found to be both linear and stable. Suitable precautions should be taken to maintain a constant current through the katharometer and to allow for the effects on the analysers of concurrent changes in concentration of helium and oxygen; these aspects are discussed in detail in a subsequent paper (Meade, in preparation).

(3) Re-design of the analyser to minimize the consequences of a non-linear calibration curve. This could be achieved by varying the depth of test gas in the light path in order to keep the output of the detector constant; the application of this nulpoint principle to the analysis of carbon monoxide is at present under consideration.

Evidence that improved accuracy is to be anticipated as a result of this trial is provided by the results of a comparable co-operative study carried out in the United States (Shepherd, 1947). In this trial gas cylinders containing $0.0393 \%$ and $0.0108 \%$ carbon monoxide in air were distributed to laboratories where they were analysed by a number of methods. The standard deviation of corrected results for the first sample distributed was $7.9 \%$ of the mean value, which is not dissimilar to the values of between 8.6 and $12.6 \%$ found in the present series. The standard deviation was reduced to $5.5 \%$ of the mean value for the second sample. Even better reproducibility between laboratories was obtained for helium in the present investigation; it is to be hoped that in future comparable precision will be obtained for carbon monoxide.

\section{SUMMARY}

Twenty-one laboratories analysed in pairs three mixtures of carbon monoxide and helium in air such as are commonly found in the determination $\underset{\overrightarrow{0}}{\vec{f}}$ of pulmonary diffusing capacity by the single $\overline{0}$ breath method. The results for helium showed good reproducibility within laboratories and relatively little scatter between them; accurate results were $\mathbb{Q}$ obtained for the analysis of ratios of concentrations and there was no evidence of inter-laboratory bias. The results for carbon monoxide showed satisfactory $\vec{\circ}$ reproducibility within laboratories: however, there $\overrightarrow{\mid}$ was much scatter between laboratories in the analysis ${ }_{\sigma}$ of absolute concentrations. Similar scatter between $\overrightarrow{\vec{z}}$ laboratories in the United States was observed by Shepherd. Evidence was obtained for inter-labora- $\infty$ tory bias in the analysis of ratios of concentrations $\stackrel{N}{\sim}$ of carbon monoxide. On this account, results $\mathcal{G}$ reported by different laboratories for a 'diffusing capacity' of $14.7 \mathrm{ml} . / \mathrm{min} . / \mathrm{mm}$. $\mathrm{Hg}$ ranged from $6.7 \mathrm{ml} . / \mathrm{min} . / \mathrm{mm}$. $\mathrm{Hg}$ to $24.8 \mathrm{ml} . / \mathrm{min} . / \mathrm{mm}$. $\mathrm{Hg}$, i.e., $46 \%$ to $171 \%$ of the expected value. Ways of reducing this variability are suggested.

I am indebted to Mr. P. Wade, librarian of the Royal Society of Medicine, for acting as an intermediary in the collection of results; to Mr. W. B. Bartley, of the Infra Red Development Company, for comments on storage of standard mixtures and for suggesting an alternative instrument design; to Dr. A. Bracken and Mr. J.유 Pennington, of the British Oxygen Company, who prepared and distributed the gas mixtures; and to the $\overline{\bar{O}}$ participating laboratories whose diligence and willing 3 co-operation made the investigation possible. I am also? indebted to my colleagues, Mr. P. D. Oldham for statistical advice, N.essrs. F. Meade and M. Saunders who performed the supplementary analyses, and N.rs. C.O John who made the computations.

\section{REFERENCES}

Forster, R. E., Fowler, W. S., Bates, D. V., and Van Lingen, B. (1954) $J$. clin. Invest., 33, 1135

Krogh, M. (1915). J. Physiol. (Lond.), 49, 271.

Shepherd, M. (1947). J. Res. nat. Bureau of Standards, 38, 351. 